\title{
GAMETOGÊNESE: ESTÁGIO FUNDAMENTAL DO DESENVOLVIMENTO PARA REPRODUÇÃO HUMANA
}

\author{
GAMETOGENESIS: FUNDAMENTAL STAGE THE DEVELOPMENT FOR HUMAN REPRODUCTION
}

\begin{abstract}
Carlos Henrique Medeiros de Araújoํㅜ, Maria Cristina Picinato Medeiros de Araújo², Wellington de Paula Martins ${ }^{3}$, Rui Alberto Ferriani ${ }^{4}$, Rosana Maria dos Reis ${ }^{4}$
\end{abstract}

\begin{abstract}
'Doutor em Biologia da Reprodução; ${ }^{2}$ Bióloga do Setor de Reprodução Humana; ${ }^{3}$ Pós-Graduando; ${ }^{4}$ Docentes. Setor de Reprodução Humana do Departamento de Ginecologia e Obstetrícia da Faculdade de Medicina Ribeirão Preto - USP.

Correspondência: Carlos Henrique Medeiros de Araujo. Departamento de Ginecologia e Obstetrícia. Faculdade de Medicina de Ribeirão Preto - USP: 14048-900 - Ribeirão Preto / SP. telefone 3602222, email:_cm.araujo@uol.com.br
\end{abstract}

Araújo CHM, Araújo MCP, Martins WP, Ferriani RA, Reis RM. Gametogênese: Estágio fundamental do desenvolvimento para reprodução humana. Medicina (Ribeirão Preto) 2007; 40 (4): 551-8, out./dez.

RESUMO: A reprodução é o mecanismo essencial para perpetuação e diversidade das espécies, assim como para a continuidade da vida. Os gametas são os veículos de transferência dos genes para as próximas gerações. A gametogênese pode ser caracterizada por três etapas distintas denominadas multiplicação (mitose), crescimento e maturação (meiose), que se diferenciam em vários aspectos na espermatogênese e na oogênese. A oogênese diferencia-se da espermatogênese na ocorrência do processo ao longo da vida do indivíduo, no número de gametas formados, nas etapas de multiplicação, crescimento e maturação, assim como nas diferenciações e maturações citoplasmáticas e nucleares dos gametas masculinos e femininos. O processo da oogênese em relação à maturação oocitária ainda merece mais estudos, pois os aspectos bioquímicos e genéticos deste processo precisam ser mais bem esclarecidos. Por meio da gametogênese masculina e feminina a natureza proporcionou a fertilidade e a capacidade de gerar filhos a casais de diferentes espécies que se reproduzem sexuadamente incluindo a espécie humana. Quando existem falhas neste mecanismo por diferentes motivos como oligospermia, teratozoospermia, astenoospermia, azoospermia, ou distúrbios da ovulação, endometriose, fatores tubários, esterilidade sem causa aparente, casais podem recorrer às tecnologias de Reprodução Assistida como inseminação intra-uterina, fertilização in vitro, injeção intra-citoplasmática de espermatozóides, e de maturação oocitária in vitro para chegarem à plenitude da reprodução.

Descritores: Gametogênese. Meiose. Técnicas Reprodutivas Assistidas.

\section{1- INTRODUÇÃO}

A reprodução é o mecanismo essencial para perpetuação e diversidade das espécies, assim como para a continuidade da vida. As diferentes espécies possuem grande variedade de mecanismos de propagação nos diferentes ambientes que se encontram como os mecanismos de reprodução sexuada, reprodução assexuada, partenogênese, entre outros.
Os gametas são os veículos de transferência dos genes para as próximas gerações. Apesar das dificuldades de estudos das células germinativas em seus micro-ambientes como as estruturas foliculares dos ovários e da maturação de oócitos in vitro muitos avanços científicos e tecnológicos já foram conseguidos na obtenção de bebes saudáveis na espécie humana por técnicas de reprodução assistida $^{1}$. 
A gametogênese humana é o fenômeno biológico de formação dos oócitos secundários e espermatozóides. A gametogênese pode ser caracterizada por três etapas distintas denominadas multiplicação (mitose), crescimento e maturação (meiose), que se diferenciam em vários aspectos na espermatogênese e na oogênese.

\section{2- OOGÊNESE}

A gametogênese feminina é denominada oogênese ou ovogênese e inicia-se no interior dos folículos ovarianos, que são as unidades funcionais e fundamentais dos ovários. Tem início ainda na vida intrauterina, quando as células germinativas, derivadas do embrião feminino, passam pela fase de multiplicação até aproximadamente a $15^{\mathrm{a}}$ semana da vida fe$\mathrm{tal}^{2}$, sofrendo divisões mitóticas dando origem as oogônias.

As oogônias a seguir passam por uma fase de crescimento dando origem aos oócitos primários.

Os oócitos primários passarão pelas fases de maturação que correspondem às divisões meióticas. Nas recém-nascidas, parte deste processo de maturação já ocorreu, isto é, a primeira divisão da meiose já se iniciou e o oócito primário encontra-se estacionado em prófase I na subfase de diplóteno ${ }^{3}$.

Alguns estudos sugerem que o processo meiótico fica inibido pela ação de um fator inibidor da maturação do oócito (OMI). Além deste fator é importante também à ação do fator promotor da maturação (MPF), que é um dímero, complexo protéico formado por duas subunidades denominadas Cdc (proteína quinase) e a ciclina, que é uma proteína reguladora, que controla a capacidade da Cdc fosforilar proteínas - alvo adequadas ${ }^{4}$.

A atividade do MPF é controlada pelo padrão cíclico de acúmulo e degradação da ciclina, que é um de seus componentes. A montagem do dímero Cdc-ciclina, sua ativação e posterior degradação são processos centrais que controlam o ciclo celular. A Figura 1 mostra a variação do complexo MPF desde o estágio de diplóteno até a metáfase II, que são dois estágios em que a meiose fica estacionada ao longo do processo de maturação.

No diplóteno da prófase I os cromossomos estão duplicados e apresentam duas cromátides. Nessa fase podem ser observados os quiasmas (pontos de cruzamentos entre cromátides não irmãs), devido à ocorrência do crossing - over.

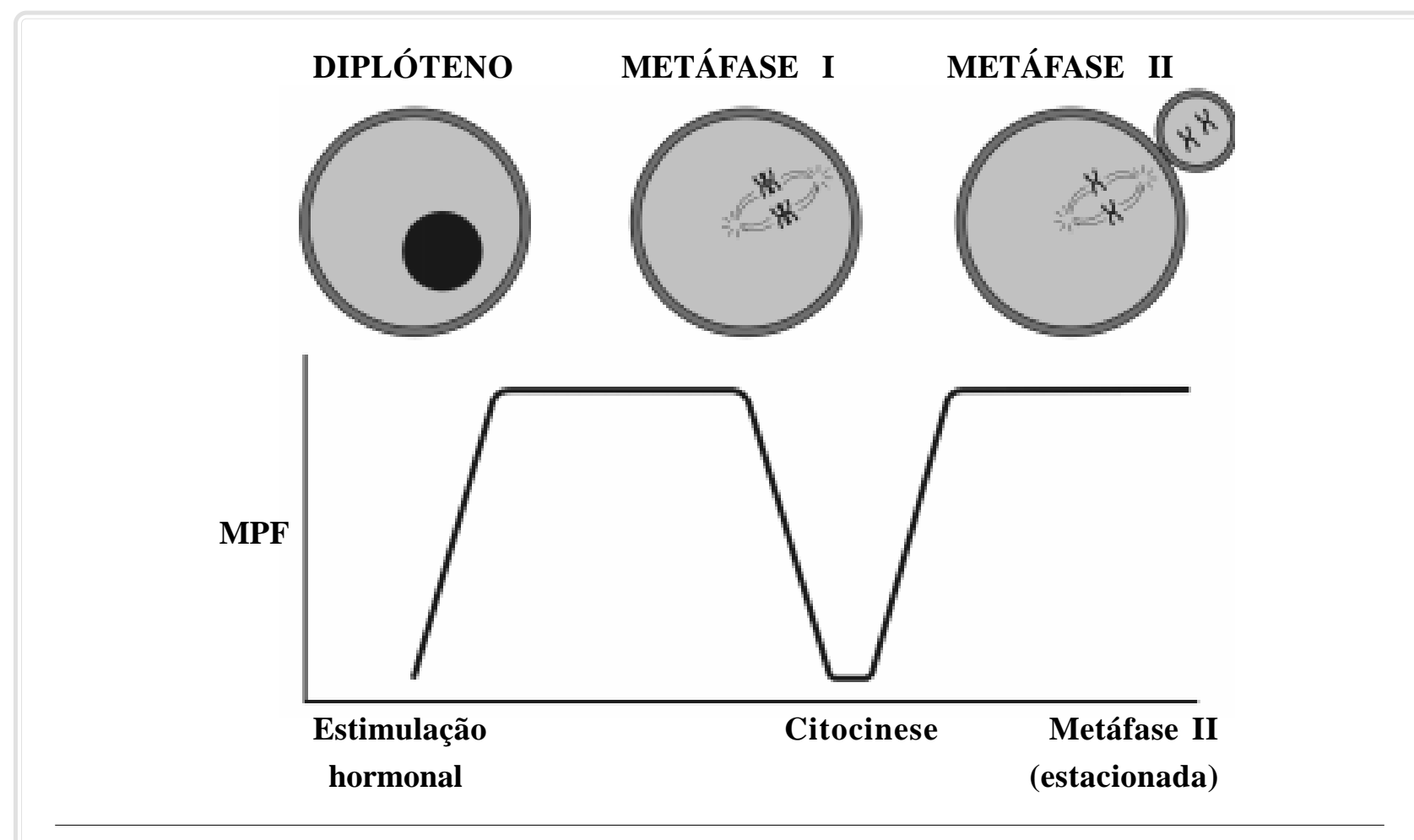

Figura 1: Variação do complexo MPF ao longo do processo de maturação oocitária. 
O oócito neste estágio é identificado morfologicamente pela visualização da vesícula germinativa, que caracteriza o oócito com núcleo bem desenvolvido, imaturo e em final de prófase I.

A quebra da vesícula germinativa marcará a continuidade da meiose e do processo de maturação oocitária ${ }^{5}$.

Os oócitos ficam neste estágio de prófase I (diplóteno) até a mulher atingir a puberdade e o processo se completará apenas na adolescência por influência das gonadotrofinas hipofisárias.

Os ovários apresentam nas mulheres recémnascidas uma média de um a dois milhões de folículos primordiais $^{6}$. Os folículos primordiais são unidades formadas por uma camada de células achatadas que envolvem o oócito primário. A partir do folículo primordial forma-se o folículo secundário e em seguida o folículo pré-antral, caracterizado pela proliferação de células da granulosa, que ficam evolvidas pelas células da teca.

Entre as células da granulosa é secretado o fluído folicular que se acumula no espaço intersticial promovendo a formação da cavidade antral, caracterizando o folículo antral. Com a formação do antro, o oócito primário passa a ocupar uma posição deslocada para um dos lados do folículo ficando rodeado por várias camadas de células denominadas de cumulus oophorus. O fluído folicular acumulado na cavidade antral é importante na nutrição das células da granulosa e do oócito.

Em ciclos naturais, o desenvolvimento folicular desde a fase de folículo secundário, quando o folículo atinge 2 a $5 \mathrm{~mm}$, até a fase antral sofre influência do Hormônio Folículo Estimulante (FSH) secretado pela hipófise anterior. Nesta fase os folículos tornam-se gonadotrofina - dependentes para seu desenvolvimento.

Sob a ação do FSH, ocorre o crescimento e o desenvolvimento folicular e o folículo antral chega à fase de folículo pré - ovulatório ${ }^{7}$. Próxima à ovulação, o pico do Hormônio Luteinizante (LH) induz a quebra da vesícula germinativa e o processo de meiose é reiniciado.

O oócito primário que estava estacionado em diplóteno, que é a fase mais longa da prófase I, podendo durar ao redor de 40 anos, entra em diacinese, finalizando a prófase I. A seguir o oócito I atinge a metáfase I em que os pares de cromossomos homólogos duplicados, pareados e num grau de condensação maior distribuem-se na placa equatorial da célula.
A continuidade da maturação oocitária é caracterizada pela chegada do oócito I a anáfase I. Nesta fase os pares de cromossomos homólogos que estão pareados migram para os pólos opostos da célula. A orientação da disjunção dos cromossomos homólogos para os pólos da célula é realizada pelo encurtamento das fibras do fuso meiótico. Esta separação dos cromossomos homólogos na anáfase I caracteriza a meiose como um processo reducional em que a ploidia da célula é reduzida à metade, isto é, o número de cromossomos $2 \mathrm{~N}=46$ cromossomos passa para $\mathrm{N}=23$ cromossomos.

A redução do número de cromossomos à metade da ploidia nos gametas é fundamental para a estabilidade do número de cromossomos da espécie. A ploidia é reconstituída no momento da fecundação.

Quando o oócito I atinge a telófase I, estará terminada a primeira divisão da meiose sendo formado o oócito secundário $(\mathrm{N})$ e um corpúsculo polar $(\mathrm{N})$. O oócito secundário é o verdadeiro gameta feminino que é liberado com o rompimento do folículo ovulatório.

A ação do LH é importante para a formação do corpo lúteo a partir do folículo ovulatório ${ }^{8}$, que sofre degeneração se não ocorrer à fecundação. A Figura 2 mostra os vários estágios do processo de maturação folicular desde o estágio de folículo primordial até a liberação do oócito secundário no fenômeno da ovulação.

No ciclo ovulatório muitos folículos podem passar pelos processos de crescimento e diferenciação, mas é comum que apenas um deles chegue à ovulação ocorrendo o processo de atresia para os folículos menores. Ao longo da vida da mulher o processo de atresia é responsável pela redução de milhões de folículos. Uma mulher durante a vida reprodutiva produz a partir da puberdade um oócito secundário a cada ciclo de ovulação, que em média ocorre a cada 28 dias, assim aproximadamente 400 folículos é que efetivamente vão liberar o oócito secundário a partir da menarca até a menopausa ${ }^{6}$.

O oócito secundário, agora com um conjunto haplóide (N) de cromossomos inicia a segunda divisão da meiose passando pela prófase II, atingindo a metáfase II. A segunda divisão da meiose é novamente bloqueada em metáfase II e será concluída se ocorrer a fertilização.

Ao longo da maturação oocitária a formação do primeiro corpúsculo polar é um sinal da finalização da meiose I, e a formação do segundo corpúsculo polar é um indicativo da fertilização do oócito. 


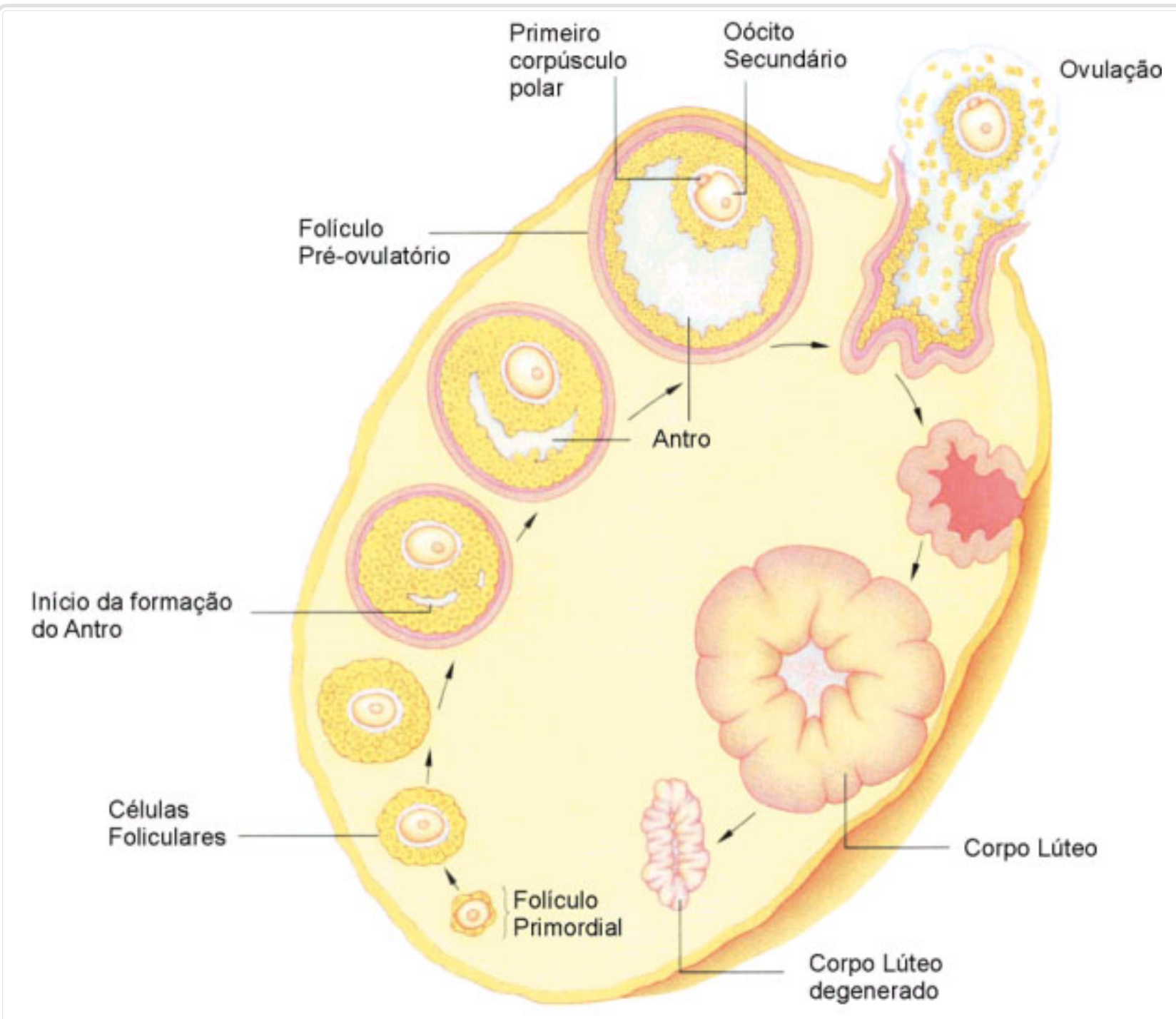

Figura 2: A figura mostra o processo de maturação folicular desde o folículo primordial até o folículo pré - ovulatório, que em seguida passa pelo fenômeno da ovulação com a liberação do oócito secundário. Adaptado de Biology a Human Emphasis. ${ }^{9}$

\section{3- ESPERMATOGÊNESE}

A gametogênese masculina é denominada espermatogênese e ocorre nos túbulos seminíferos dos testículos. É um processo contínuo na vida do homem após ser atingida a puberdade. A maturação das células germinativas para formação dos espermatozóides ocorre até o final da vida do indivíduo, em que cada espermatogônia dará origem a quatro espermatozóides.

As espermatogônias que foram formadas durante a vida fetal e estavam dormentes nos túbulos seminíferos, entram em fase de multiplicação na puberdade dando origem a muitas espermatogônias por mitoses sucessivas ${ }^{10}$.

Após a fase de multiplicação, cada espermatogônia formada entra na fase de crescimento e dá origem a dois espermatócitos primários. Em seguida os espermatócitos primários passam pela fase de maturação, que corresponde às divisões de meiose.

Cada espermatócito primário ao sofrer a primeira divisão da meiose dá origem a dois espermatócitos secundários. Esta primeira divisão da meiose é reducional, assim os espermatócitos secundários pas- 
sam a ter metade do número de cromossomos, isto é, cada espermatócito secundário é uma célula haplóide $(\mathrm{N})$, ao contrário dos estágios anteriores de espermatogônias e espermatócitos primários que são diplóides $(2 \mathrm{~N})$.

A continuidade do processo de maturação ocorre com a segunda divisão da meiose nos espermatócitos secundários que darão origem as espermátides, que também são células haplóides. Cada espermátide passa pelo fenômeno da espermiogênese, que corresponde ao processo de diferenciação celular para formação dos verdadeiros gametas masculinos. Durante a espermiogênese as espermátides ganham o acrossomo e a cauda (flagelo). O acrossomo está localizado na região anterior da cabeça do espermatozóide e corresponde a uma aglomeração de vesículas secretadas a partir do complexo de Golgi.

No acrossomo estão presentes várias enzimas, entre elas a hialuronidase que têm papel fundamental no momento da fecundação, pois as atividades destas enzimas favorecem a entrada do espermatozóide através da corona radiata e da zona pelúcida durante o processo de fertilização.
A cauda do espermatozóide é fundamental para a mobilidade do gameta masculino até o local da fertilização. Para ocorrer o movimento de chicoteamento da cauda do espermatozóide, as mitocôndrias da cauda fornecem ATP (adenosina trifosfato), que é fonte de energia para a locomoção ${ }^{11}$.

A espermatogênese desde a origem das espermatogônias até a formação dos espermatozóides, passando pela espermiogênese, ocorre em aproximadamente dois meses ${ }^{10}$.

A Figura 3 mostra o momento da penetração do espermatozóide através das células foliculares para atingir o oócito secundário. O oócito fertilizado sofrerá clivagens originando o embrião, que se desenvolverá no interior do útero materno.

A gametogênese feminina diferencia-se da masculina em vários aspectos como na ocorrência do processo ao longo da vida do indivíduo, no número de gametas formados, nas etapas de multiplicação, crescimento e maturação, assim como nas diferenciações e maturações citoplasmáticas e nucleares dos gametas masculinos e femininos. A Tabela I mostra as principais diferenças na gametogênese humana.

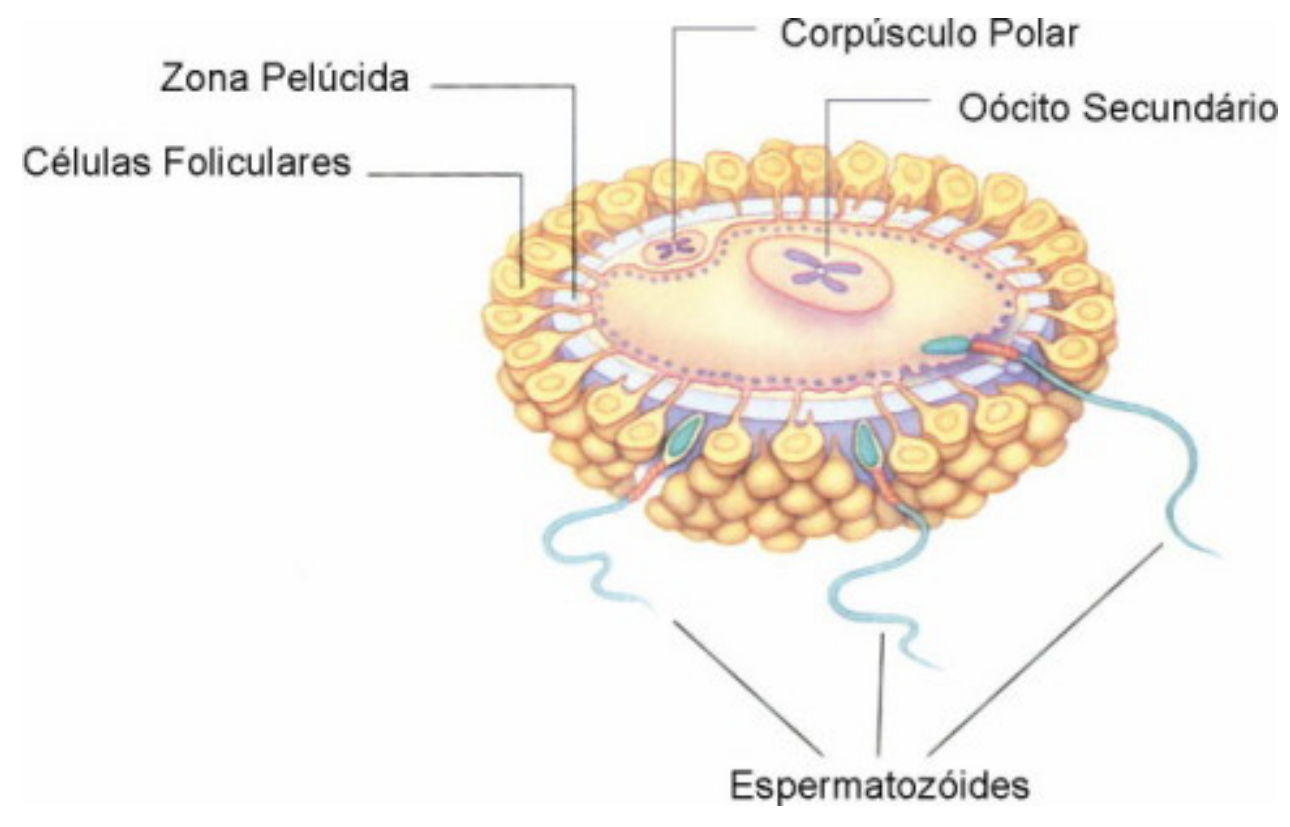

Figura 3: O esquema mostra o momento da penetração do espermatozóide no oócito secundário. Adaptado de Biology a Human Emphasis ${ }^{9}$. 
Tabela I: Parâmetros que diferenciam a oogênese da espermatogênese

\begin{tabular}{lll}
\hline & Gametogênese feminina & Gametogênese masculina \\
\hline Duração & $\begin{array}{l}\text { Inicia-se na vida embrionária e é retoma- } \\
\text { da no período menacne - menopausa. }\end{array}$ & $\begin{array}{l}\text { Inicia-se na puberdade e pode ocor- } \\
\text { rer durante toda vida. }\end{array}$ \\
Gametas formados & 1 oócito para cada oogônia & $\begin{array}{l}\text { nespermatozóides por espermatogô- } \\
\text { nia }\end{array}$ \\
Etapa de multiplicação & $\begin{array}{l}\text { Ocorre na vida intra-uterina (até o 30 mês } \\
\text { do desenvolvimento embrionário). }\end{array}$ & $\begin{array}{l}\text { Ocorre ao longo da vida a partir da } \\
\text { puberdade. }\end{array}$ \\
Etapa de maturação & $\begin{array}{l}\text { Meiose I - oócito II e 1 corpúsculo polar } \\
\text { Meiose II - pré - embrião e 2 corpúscu- } \\
\text { los polares }\end{array}$ & $\begin{array}{l}\text { Meiose I - 2 espermatócitos II - 4 espermatozóides } \\
\text { Meiose }\end{array}$ \\
\hline Diferenciação citoplasmática & $\begin{array}{l}\text { Divisão desigual com formação de cor- } \\
\text { púsculos polares }\end{array}$ & Formação de acrossomo e flagelo \\
\hline
\end{tabular}

\section{4- AÇÃO DAS GONADOTROFINAS E FATO- RES DE INIBIÇÃO OU DE PROMOÇÃO DA MEIOSE}

Para ocorrência da maturação oocitária, além da ação das gonadotrofinas deve ocorrer à redução dos fatores de inibição da maturação oocitária, além da presença de nutrientes estruturais e energéticos específicos necessários ao metabolismo da maturação. As gonadotrofinas induzem a quebra da vesícula germinativa de oócitos crescidos do folículo antral ou de oócitos isolados e envolvidos por células do cumulus in vivo ou em modelos experimentais in vitro.

As gonadotrofinas não apresentam o mesmo efeito em oócitos pobres em células somáticas do cumulus. Neste mecanismo podem estar envolvidos estímulos positivos gerados pelas células foliculares e/ou falta de fatores que determinam à inibição da meiose $^{12}$.

As gonadotrofinas estimulam aumento de adenosina monofosfato cíclico (cAMP) e ativam os níveis de proteína quinase ativadora da meiose nas células da granulosa. Ocorre passagem de sinais indutores da meiose pelas células da granulosa que estão em comunicação com o oócitos pelas Gap Junctions. Esta ativação ocorre por meio da ativação das proteínas quinases e fatores promotores da meiose (MPF). Quando as Gap Junctions entre células da granulosa e oócitos são desfeitas, termina a transmissão de fatores que estacionam a meiose do oócito ${ }^{13}$. O número de moléculas de proteínas quinases reguladas pelas ciclinas (Cdc - cilina B), que formam o MPF, aumenta muito quando o oócito adquire competência para sofrer a quebra da vesícula germinativa e reinicializar a meiose $^{14}$.

No início do período G1 da interfase ocorre a formação dos complexos de pré-replicação de DNA, a desativação do complexo promotor da anáfase (APC) e ativação dos componentes protéicos do período $S$ da interfase, que atuarão na duplicação do DNA. Entre os períodos $\mathrm{G} 2$ da interfase e prófase os complexos protéicos MPF ativam a condensação dos cromossomos, o rompimento da carioteca e a formação das fibras do fuso de divisão. Durante a metáfase este complexo MPF ativa o complexo promotor da anáfase (APC), a partir da fosforilação do APC inativo.

O APC degrada o inibidor da anáfase sendo possível então à migração dos cromossomos ou das cromátides para os pólos da célula caracterizando respectivamente a anáfase I e anáfase II da meiose. A atividade do MPF é dependente da proteína ciclina B, que é sintetizada entre o final do período $\mathrm{G} 2$ da interfase e início da prófase ${ }^{15}$. 
Por meio da ação do APC é degradado o inibidor da anáfase e logo em seguida ocorre também à degradação da unidade ciclina B do complexo MPF. $\mathrm{Na}$ telófase os níveis de ciclina $\mathrm{B}$ diminuem e a atividade do MPF é baixa. A partir daí a célula entra novamente em interfase (G1). A Figura 4 mostra o mecanismo de regulação do ciclo celular por meio da ação do MPF e do APC.

Muitos aspectos da oogênese em relação à maturação oocitária ainda merecem mais estudos, pois os aspectos bioquímicos e genéticos deste processo precisam ser mais estudados. Também existem muitas dúvidas sobre os mecanismos de pareamento e recombinação de cromossomos homólogos durante a prófase I da meiose. Embora muitas moléculas fundamentais para o controle do início e da parada da meiose já sejam conhecidas, muitas questões a respeito de suas origens e funções ainda devem ser esclarecidas. Outra dúvida ainda é sobre a natureza dos substratos de muitas enzimas. Além disso, a identidade de ligantes das células da granulosa envolvidos na geração de cAMP nos oócitos ou sinalizadores da reinicialização da meiose (maturação nuclear) ainda não são conhecidos. No aspecto genético, genes de efeito materno ainda devem ser descobertos no processo de maturação oocitária.

\section{5- CONSIDERAÇÕES FINAIS}

Por meio da gametogênese masculina e feminina a natureza proporcionou a fertilidade e a capacidade de gerar filhos a casais de diferentes espécies que se reproduzem sexuadamente incluindo a espécie humana. Quando existem falhas neste mecanismo por diferentes motivos como oligospermia, teratozoospermia, astenoospermia, azoospermia ou mesmo anovulação crônica, endometriose, fatores tubários ou esterilidade sem causa aparente, casais podem recorrer às tecnologias de Reprodução Assistida como inseminação intra-uterina, fertilização in vitro, injeção intra-citoplasmática de espermatozóides, e de maturação oocitária in vitro para chegarem à plenitude da reprodução.

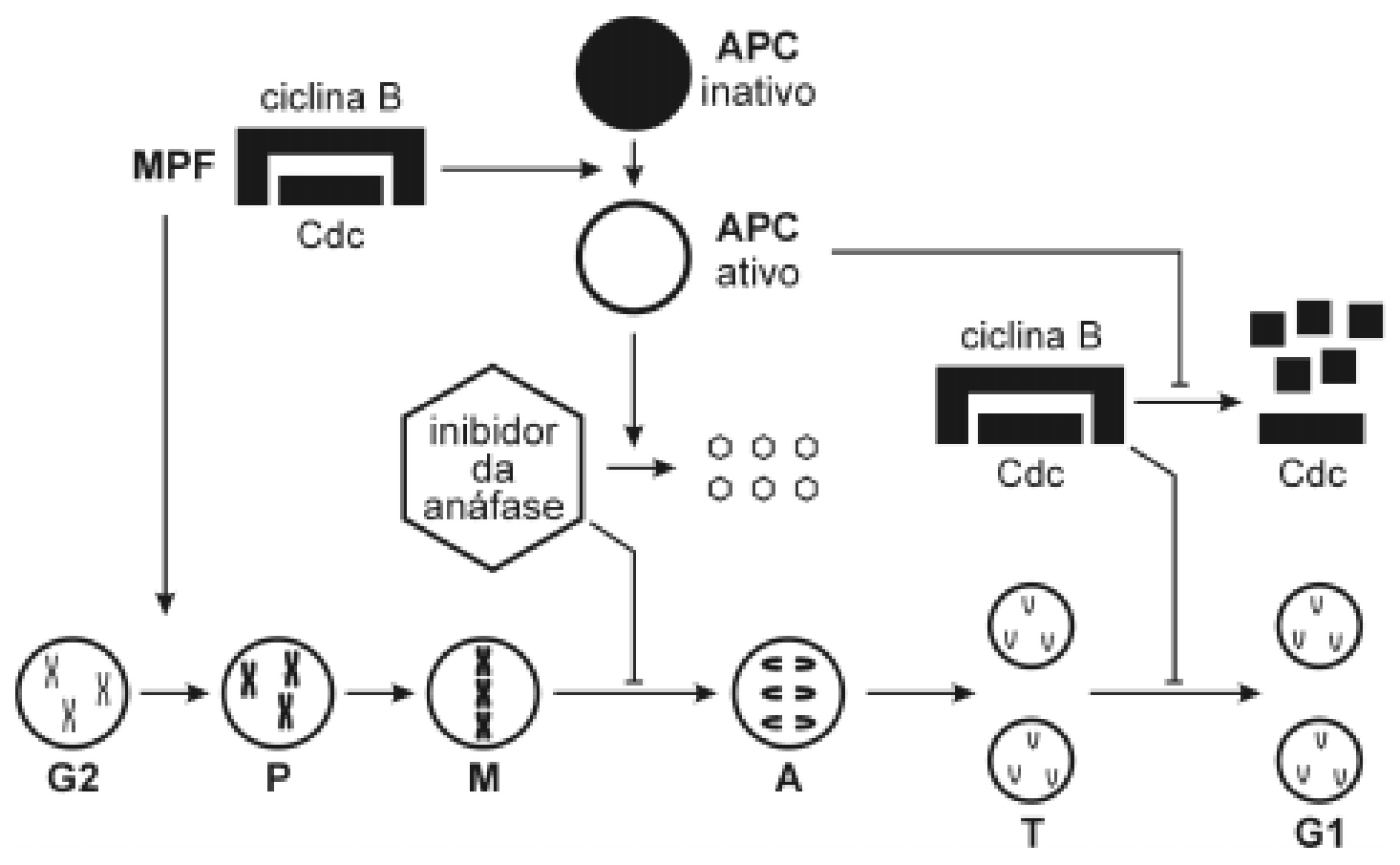

Figura 4: Mecanismo de regulação do ciclo celular por meio da ação do fator promotor da meiose (MPF) e do complexo promotor da anáfase (APC). G1 e G2 (interfase), P (prófase), M (metáfase), A (anáfase), T (telófase). 
Araújo CHM, Araújo MCP, Martins WP, Ferriani RA, Reis RM. Gametogenesis: fundamental stage the development for human reproduction. Medicina (Ribeirão Preto) 2007; 40 (4): 551-8, oct./dec.

ABSTRACT:The reproduction is the essential mechanism for perpetuation and diversity of the species, as well as for the continuity of the life. The gametes are the vehicles of transfer of the genes for the next generations. The gametogenesis can be characterized by three stages denominated different multiplication (mitosis), growth and maturation (meiosis), which differ in several aspects in the spermatogenesis and in the oogenesis. The oogenesis differs of the spermatogenesis in several aspects as in the occurrence of the process along the individual's life such as in the number of formed gametes, in the multiplication stages, growth and maturation, as well as in the differentiations and cytoplasmtic and nuclear maturations of the masculine and feminine gametes. The process of the oogenesis in relation to the oocyte maturation still deserve many studies, because the biochemical and genetic aspects of this process need to be better explained. Through the masculine and feminine gametogenesis the nature provided the fertility and the capacity of generating children to you marry of different species that sexually reproduce including the human species. When flaws exist in this mechanism for different reasons as oligospermy, teratozoospermy, astenoospermy, azoospermy or ovulation disturbs, endometriosis, tubal factors, or unexplained infertility couples can fall back upon the technologies of Assisted Reproduction as in vitro fertilization, intracytoplasmic sperm injections, artificial insemination, in vitro maturation of oocytes to reach the fullness of the reproduction.

Keywords: Gametogenesis. Meiosis. Reproductive Techniques, Assisted.

\section{REFERÊNCIAS}

1 - Roy A, Matzuk MM. Deconstructing mammalian reproduction: using knockouts to define fertility pathways. Reproduction 2006; 131: 207-19.

2 - Houillon C. Espermatogênese e Ovogênese. In: Houillon C. Sexualidade. São Paulo: Edgard Blucher; 2001. p. 17-36.

3 - Buccione R, Schroeder AC, Eppig JJ. Interactions between somatic cells and germ cells throughout mammalian oogenesis. Biol Reprod 1990; 43: 543-7.

4 - Scott JRT, Hodgen GD. The ovarian follicle: life cycle of a pelvic clock. Clin Obstet Gynecol 1990; 3: 55-62.

5 - Veeck LL. Gamete Maturation. An atlas of human gametes and conceptuses an illustrated reference for assisted reproductive technology, New York, NY: The Parthenon Publishing; 1999; p. 15-24.

6 - Salha O, Busheika NA, Sharma V. Dynamics of human follicular growth and in vitro oocyte maturation. Hum Reprod Update 1988; 4: 816-32.

7 - Adashi EY, Rock JA, Rosenwaks Z. The ovarian follicular apparatus. Reproductive Endocrinology Sugery, and technology. New York, NY: Lippincott-Raven ; 1995. p. 18-40

8 - Chian RC, Bucckett WM, Tan SL. In-vitro maturation of human oocytes. Reprod Biomed 2003; 8: 148-66.

9 - Starr C. Reproduction and Development. In: Starr C. Biology a human emphasis. $3^{\text {nd }}$. Belmont, California: Wadsworth Publishing; 1984. p. 590-627.
10 - Moore KL, Persaud TVN. Início do desenvolvimento humano: primeira semana. In: Moore KL, Persaud TVN. Embriologia

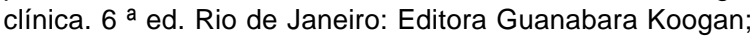
2000. p.15-43.

11 - Oura C, Toshimori K. Ultrastructural studies on the fertilization of mammalian gametes. Int Rev Cytol 1990; 122:105- 51.

12 - Downs SM, Daniel SAJ, Eppig JJ. Induction of maturation in cumulus cell-enclosed mouse oocytes by follicle-stimulating hormone and epidermal growth factor. Evidence for a positive stimulus of somatic cell origin. J Exp Zool 1988; 245: 61-71.

13 - Su YQ, Wigglesworth K, Pendola FL, O‘Brien MJ, Eppig JJ. Mitogen-actived protein kinase (MAPK) activity in cumulus cells is essential for gonadotropin-induced oocyte meiotic resumption and cumulus expansion in the mouse. Endocrinology 2002; 143: 2221-32.

14 - Kanatsu-Shinohara M, Schultz RM, Kopf GS. Acquisition of meiotic competence in mouse oocytes: Absolute amounts of p34(cdc2), cyclin b1, cdc25C, and weel in meiotically incompetent and competent oocytes. Biol. Reprod 2000; 63: 1610-6.

15 - Burrows AE, Sceurman BK, Kosinski ME, Richie CT, Sadler $\mathrm{PL}$, Schumacher JM, et al. The C. elegans Myt1 ortholog is required for the proper timing of oocyte maturation. Development 2006; 133: 697-709.

Recebido em 22/06/2007

Aprovado em 31/07/2007 